\title{
Intermittent Fasting Decreases Oxidative Stress Parameters and Increases Total Antioxidant Capacity
}

\author{
Samar I. Sharsher 1,*iD, Amany I. Ahmed ${ }^{2}$, Mohamed Metwally ${ }^{3}$, Ahmed Hamed Arisha ${ }^{4}$, Khalifa El- \\ Dawy Ahmed ${ }^{2}$

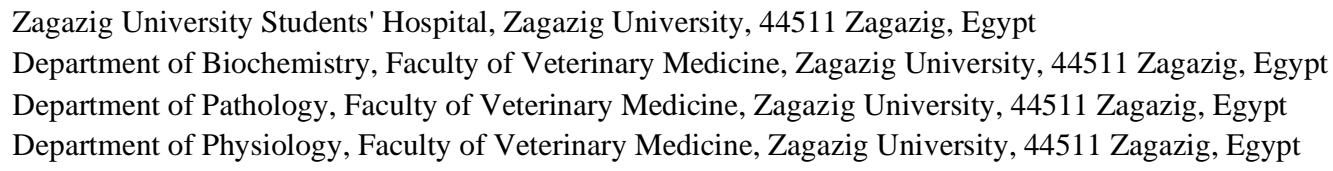

Received: 19.09.2021; Revised: 15.10.2021; Accepted: 18.10.2021; Published: 20.11.2021

\begin{abstract}
Modern lifestyle with an unhealthy routine, including consumption of excessive food and less physical activity, is full of many complications like chronic and degenerative diseases. For driving a healthy life, following a prophylactic style is necessary. The simplest and available way is intermittent fasting (IF). IF can help weight management. IF may lower oxidative stress. Oxidative stress can be determined from the malondialdehyde (MDA) levels and tri acyl glycerol (TAG) in the blood. Also, it increases Total antioxidant capacity (TAC). This study aimed to determine the effect of both protocols, Alternate day fasting (ADF) and time-restricted feeding (TRF), on plasma MDA level, TAG concentration, and TAC level of Sprague Dawley rats. They were randomly assigned to 3 groups, i.e., control group (C), fasting group (ADF), fasting group (TRF). Fasting given in this research was ADF, comprising one day of fasting for 24 hours, alternating with one day of normal feed ad libitum in the span of 12 weeks, including fasting 12 hours for two days a week plus three days in the middle of the month. After 3-months, blood was taken for examination of MDA levels, TAG, and TAC levels. A significant difference among the three groups in MDA levels, TAG and TAC. $(\mathrm{p}<0.05$ for all parameters). Groups conducted on intermittent fasting had lower levels of MDA, TAG concentration, and a high level of TAC. ADF was lower in MDA level and TAG concentration than TRF. ADF was higher in TAC level than TRF. Intermittent fasting (ADF and TRF) decreases the oxidative stress parameters and increases Total antioxidant capacity in Sprague Dawley rats. ADF is more effective than TRF.
\end{abstract}

Keywords: intermittent fasting; ADF;TRF; MDA; oxidative stress; TAC.

(C) 2021 by the authors. This article is an open-access article distributed under the terms and conditions of the Creative Commons Attribution (CC BY) license (https://creativecommons.org/licenses/by/4.0/).

\section{Introduction}

Modem lifestyle complications have been nearer to everyone worldwide, increasing the risk of Metabolic disorders such as type 2 diabetes, cancer, cardiovascular diseases, and immune system dysfunctions, which is an ugly fear of everybody that have been related to obesity $[1,2]$. Intermittent fasting (IF) protocols can be a promising approach for weight loss and blood chemistry improvement in persons who can safely tolerate it. IF protocol is a sustainable and viable style that may be used to promote health [3]. IF ameliorates glycemic control. Although most studies were carried out considering the metabolic importance, which can be expected due to following IF. The weight of the evidence to date advises that IF could have an effective role in the management of disorders of chronic metabolic diseases like obesity and type 2 diabetes [4]. 
Most studies associated with obesity diseases are related to oxidative stress and include inflammatory mechanisms [5,6]. IF provides multiple pathways to produce its influences, such as decreasing oxidative stress, ketogenesis, and circadian rhythms. Also, IF can minimize cardiovascular diseases risk in association with the management of weight, dyslipidemia, hypertension, and diabetes [7]; the risk of chronic diseases like cardiovascular and cancer can be lowered by lowering oxidative stress through intermittent fasting, which can be defined as periods of fasting starting from 12 to 48 hours and is the most under-investigated fasting regimen $[8,9]$. The most common types of IF are alternate day fasting (ADF) and time-restricted feeding (TRF). It has been known that IF can elevate life- and health-span by weight and fat loss and through causing a decline in reactive oxygen species (ROS) production and amelioration of glucose regulation, lipid metabolism, increased cellular stress resistance, and inflammation reduction $[10,11]$.

Generally, 10-16 hours after the last meal, blood sugar, insulin, and IGF-1 levels decline, while glucagon and growth hormone rise. Ketone bodies are consumed as sources of energy and facilitate the expression and activity of different transcription factors that are known as "metabolic switch" from liver-derived glucose to adipose-cell-derived ketones (G-to-K) and the opposite pathway K-to-G upon reuptake of food [12,13].

IF can introduce useful effects through the improvement of anthropometric parameters and composition of the body and Lipid profile in obese adult individuals [14]. Also, another human study of ADF has cleared that ADF is a viable diet regimen for weight loss, and it has a significant improvement in risk indicators for diseases in obese or normal people [15].

Both IF and energy-restricted diets have a strong influence to ameliorate total circulating cholesterol, low-density lipoprotein-C, and triacylglycerol (TAG). However, it has no significant influence on High-density lipoprotein-C. The finding of this study cleared that the dietary regimens are ways of lipid profile enhancing in individuals [16]. It has been reported that IF in both animal and human models can improve cardiovascular health by improving plasma lipid profile, as several ADF trials in man reduce TAG and LDL levels. [17].

Also, in a recent human study, TRF with shorter intervals has reported useful effects like weight loss and reduced oxidative stress in obese humans [18], similar useful influences associated with health improvements of IF were noticed in non-obese individuals [19].

The useful effects of fasting on redox balance are carried out by minimizing oxidative damage. Several species show signs of oxidative stress related to metabolically extreme processes, but fasting of wild vertebrates buffers themselves in several ways like increasing antioxidants, modifying behavioral patterns, and maintaining redox balance in certain tissues [20].

The most famous indicator of the determination of oxidative stress is blood MDA concentration measurement [6]. Many studies have been carried out on fasting. For example, studies that limit calories amounts in healthy rats[21]. Other various studies of intermittent fasting like Ramadan fasting, Greek orthodox, Daniel fasting [22].

In a study of Wister rats which were conducted on ADF fasting [5], each of these studies conducted different techno. In ADF of Wister rats, fasting 12 hours a day followed by normal day feeding (ad libitum) has shown a significant decrease in oxidative stress parameters (MDA level and TAG concentration). The present study provides two protocols of IF; ADF 24 hours fasting, followed by 24 hours normal day feeding. TRF fasting 12 hours a day (12 hours night fasting) only for two days a week (Monday and Thursday) plus three middle days in the month. 
On the contrary, fasting in the long term may increase oxidative stress, which is known by increasing reactive oxygen species (ROS) [23], increasing saturated fatty acid level, and lipid peroxidation [24]. Increasing oxidative stress is a strong indicator of degenerative diseases. When a state of high production of ROS increases and accumulates in tissues and the biological system becomes unable to detoxify them, this is called oxidative stress [25].

The body of a human being is able to deal with oxidative stress through enzymatic and non-enzymatic antioxidants, superoxide dismutase (SOD), glutathione peroxidase (GPx), and catalase (Cat), which are the most abundant enzymes [12]. The body is protected from superoxide by SOD which is the main antioxidant enzyme. Superoxide is catalyzed by SOD to become hydrogen peroxide, then by GPx and Cat to be converted into water [25-27], which are able to lower oxidative stress [27]. In the case of IF oxidative stress induces the antioxidant system to get rid of the free radicals, which repairs cell damage [28].

In other studies of intermittent fasting as a typical Ramadan fasting, there was neither elevation in oxidative stress nor antioxidants [27]. Ramadan fasting provides many health benefits as it decreases the risk of diabetes, cardiovascular diseases, and antihypertension[25]. In Dawood fasting [27], there was the induction of an elevation in antioxidants that can protect lymphocyte cell membranes from the oxidation caused by oxidative stress and increase the immunoglobulin (Ig) IgM and IgG. Therefore, an improvement in the components of the immune system is one of the body's defense mechanisms against antigens that can help lower the risk of disease [27]. On the other hand, the levels of TAC in the high-fat diet group are lower. This is because a high-fat diet causes excessive oxidative stress, resulting in an imbalance in antioxidants needed resulting in inflammation [27]. In the previous study of Wistar rats, only MDA level was measured enzymatic spectrophotometry and in a span of 8 weeks, but the present study aims to determine the effect of both ADF and TRF protocols on MDA level, TAG concentration, and plasma TAC level in a span of three months.

In one study to determine TAC level, in the plasmatic oxidative status, the carbonylation of amino acids has been known to be the most known oxidative modification in the plasma, and thiol protein groups are the most antioxidant component of the plasma [29]. So, protein carbonyl groups and thiols groups levels were determined in the plasma of control and diabetic rats. TAC was determined in rats' plasma. Food restriction(fasting) did not cause modification in the levels of protein carbonyl groups in the plasma of non-diabetic control rats. Food restriction (fasting) did not elevate the levels of thiol groups in the diabetic group, but it increased albumin levels. The total antioxidant capacity (TAC) was strongly decreased in diabetic groups (compared to the controls) [29].

The endogenous production of antioxidant molecules can be enhanced by fasting for a long time which acts against free radicals and improves the metabolic health status in a similar way[30].

\section{Materials and Methods}

\subsection{Materials.}

Forty-five male adult Sprague Dawley rats, weighing $200 \pm 50 \mathrm{~g}$, were driven from the Faculty of Veterinary Medicine central animal house, Zagazig University, Egypt. They were acclimatized for two weeks under standard laboratory circumstances. The animals were housed under conventional laboratory circumstances through the experiment period in $22 \pm 2^{\circ} \mathrm{C}$ temperature, with a 12-hour light/dark cycle and free food and water were available. All animal 
handling and experiments were conducted along with the procedures reviewed and approved by Zagazig University Institutional Animal Care and Use Committee (ZUIACUC/2/F/195/2019).

After adaptation for two weeks, rats were subdivided into three groups:

-The first one is a normal control group ( $\mathrm{G} 1, \mathrm{CON}, \mathrm{n}=15$ rats), the rats were supplied with the typical rat chow and water.

- The second group (G2, ADF, $\mathrm{n}=15)$ rats' day on day off fasting.

-The third group (G3, TRF, n=15) (rats fasting for two days a week (Monday and Thursday) plus the three middle lunar days in the month $13^{\text {th }}, 14^{\text {th }}$ and 15 th day. The eating period was through their rest time from7pm till7am.

The study lasted for three months. Blood and tissues samples were collected monthly at the end of the $1^{\text {st }}, 2^{\text {nd }}, 3^{\text {rd }}$ months by withdrawing 5 rats from each group and slaughtering them monthly. It should be understood that our approach represents a more stringent approach than the often-used "very low calorie" ADF protocol adopted in some human studies. Also, in the TRF group, we provide a new style to feed only two days per week plus three days in the middle of the month. This new style of feeding provides a more applicable and easier style to be followed by the individual. Moreover, another novelty is the time of feeding, which is 12 hours at night.

\subsection{Methods.}

2.2.1. Body weight and Anthropometric parameters.

The experimental animals were individually weighed on the first day of experimentation to record the initial body weight, then every week, the body weight of each rat was recorded, and random blood glucose was measured for three rats from each group weekly using a one-touch device.

At the end of each month, rat lengths and body waist determination were measured using centimeter graduated tape. Then BMI was calculated by dividing weight over square length.

\subsubsection{Determination of Tri acyl glycerol and Malondialdehyde (TAG and MDA) level.}

At the end of the study, blood was drawn transcardially from each rat using a 3-ml syringe, and around $2 \mathrm{ml}$ was placed in an EDTA tube. Subsequently, the blood samples were transported to the Laboratory to determine MDA concentrations and triglycerides by enzymatic spectrophotometry. The blood was then centrifuged to obtain the supernatant. To every 100 microliters of serum, $2.45 \mathrm{ml}$ of trichloracetic acid (TCA) and $2.45 \mathrm{ml}$ of thiobarbituric acid (TBA) were added, then the mixture was heated at $100^{\circ} \mathrm{C}$ for 20 minutes. Subsequently, the mixture was centrifuged for 10 minutes at $8000 \mathrm{rpm}$. The absorbance of the obtained supernatant was determined with a blank of $2.45 \mathrm{ml} \mathrm{TCA}$ and $2.45 \mathrm{ml}$ TBA based on the included standard curves. To determine MDA conc in umol/10dl.

\subsubsection{Determination of Total Antioxidant Capacity (TAC).}

The spectrophotometry measurement of Plasma TAC was carried out using 2,2-azinobis(3-ethylbenzthiazoline-6-sulphonic acid)[29]. Then by using the standard curve prepared with Trolox, a water analog of vitamin E TAC was calculated, and the result was expressed in 
$\mathrm{nmol}(\mathrm{ml} \text { plasma })^{-1}$. The spectrophotometric measurement of plasma (412 nm) was carried out using DTNB (5,5'- dithiobis 2-nitrobenzoic acid) as previously described [29]. By the molar extinction coefficient $(\varepsilon)$ of $1.36 \times 10^{4} \cdot \mathrm{M}^{-1} \cdot \mathrm{cm}^{-1}$, the calculation of thiol content was carried out and expressed as nmol(mg protein $)^{-1}$. Then the spectrophotometric measurement of protein carbonyl groups is carried out using 2,4-dinitro-phenylhydrazone [31]. By using the molar extinction coefficient $(\varepsilon)$ of $2.20 \times 10^{4} \mathrm{M}^{-1} \cdot \mathrm{cm}^{-1}$, the calculation of protein carbonyl groups was carried out and expressed as nmol (mg protein) ${ }^{1}$ to determine TAC level in nmol Trolox equ/10ml.

\subsection{Statistical analysis.}

The distribution of the obtained numerical data was determined with the Shapiro-Wilk test, followed by Levene's test to assess the homogeneity of the data. The data were analyzed by Graph Pad prism 8.0.2 (GraphPad Software, Inc). The results were reported as Mean \pm SE. Data were screened. The assumption achievement was checked at $\mathrm{P} \leq 0.05$. Twoway ANOVA was run for assumption met data to test differences among groups for certain parameters with different treatments at different experiment times. If there was a significant difference, a multiple comparison posthoc test (Tukey test) was done. The difference was considered significant if $\mathrm{p}<0.05$.

\section{Results and Discussion}

Rats were weighed at the beginning of each week of the three months, mean of rat weight change were analyzed $b$ two ways ANOVA, A significant reduction in body weight change was noticed in the ADF group starting at the 5th week 13.6 \pm 2.87 at $\mathrm{P}<0.05$ till the $12^{\text {th }} 24.3 \pm$ 7.19 at $\mathrm{p}<0.05$ week compared to the control and TRF group. In the TRF group, the significant reduction in body weight change at $\mathrm{P}<0.05$ was noticed only in $7^{\text {th }} 75 \pm 2.02,8$ th $75 \pm 2.61$, and $9^{\text {th }} 90 \pm 2.44$ weeks; all values were measured at $\mathrm{P}<0.05$ compared to the control group. The reduction in the body weight change was more pronounced in ADF than TRF groups.

\subsection{Effect of fasting protocols (ADF or TRF) on anthropometric parameters.}

Length: No significant alterations in length were noticed in the two fasting protocols followed compared to the control group (Figure 1A, Table 1).

Table 1. Anthropometric measurements in different fasting protocols.

\begin{tabular}{|c|c|c|c|c|}
\hline Time & Control & ADF & TRF & P-value \\
\hline \multicolumn{5}{|l|}{ Length } \\
\hline $1^{\text {st }}$ month & $21.75 \pm 0.44$ & $21.38 \pm 0.38$ & $20.83 \pm 0.73$ & \multirow{3}{*}{$0.692^{\mathrm{NS}}$} \\
\hline 2d month & $22.13 \pm 0.97$ & $21.25 \pm 0.25$ & $22.25 \pm 0.75$ & \\
\hline $3^{\text {rd }}$ month & $22.8 \pm 0.56$ & $21.40 \pm 0.59$ & $22.80 \pm 0.86$ & \\
\hline \multicolumn{5}{|l|}{ BMI } \\
\hline $1^{\text {st }}$ month & $0.54 \pm 0.006^{\mathrm{bc}}$ & $0.50 \pm 0.01^{\mathrm{bc}}$ & $0.55 \pm 0.03^{\mathrm{abc}}$ & \multirow[b]{3}{*}{$0.03 *$} \\
\hline $2 \mathrm{~d}$ month & $0.59 \pm 0.035^{\mathrm{ab}}$ & $0.50 \pm 0.005^{\mathrm{bc}}$ & $0.54 \pm 0.02^{\mathrm{bc}}$ & \\
\hline $3^{\text {rd }}$ month & $0.65 \pm 0.02^{\mathrm{a}}$ & $0.49 \pm 0.01^{\mathrm{c}}$ & $0.53 \pm 0.02^{\mathrm{bc}}$ & \\
\hline
\end{tabular}

Group C: control group, group ADF: alternate fasting group, TRF: time-restricted feeding group, m1:month 1,vs:versus.1.1. Length: no significant difference among the three groups and no significant difference among the three months of each group. 1.2. BMI: Two ways ANOVA, by Tukey's multiple comparisons test within each month cleared that: in ADF is a significant difference from c group in $2^{\text {nd }}$ and $3^{\text {rd }}$ months; TRF in $3^{\text {rd }}$ month is differently significant with those of c group. By further Tukey's multiple comparisons test within each group showed no significant difference among the three months in the control group, while in the ADF group, there was a significant difference at $\mathrm{P}=0.003$ in $1^{\text {st }}$ month versus $3^{\text {rd }}$ month, and in the TRF group, there was no significant difference among the three months. 
BMI: Two ways ANOVA analysis has delivered that Interaction factor $\mathrm{P}^{*}=0.0359$, Row Factor (among the three months) p-value $=0.2929$ means nonsignificant value, Column Factor (within each month) $\mathrm{P}^{* * * *}<0.0001$ which is highly significant. By further Tukey multiple comparison test within each month, we have found that within the $1^{\text {st }}$ month, there is no significant difference among the three groups. Within the $2^{\text {nd }}$ month, a significant difference of control versus $\mathrm{ADF} * \mathrm{p}=0.01(\mathrm{C}=0.59 \pm 0.035, \mathrm{ADF}=0.50 \pm 0.005)$. Within the $3^{\text {rd }}$ month, a significant difference of Control group versus $\mathrm{ADF}^{*} \mathrm{P}<0.0001(\mathrm{C}=0.65 \pm 0.02, \mathrm{ADF}=0.49 \pm 0.01)$ and Control group versus $\mathrm{TRF}^{*} \mathrm{P}=0.001(\mathrm{C}=0.65 \pm 0.02, \mathrm{TRF} \pm 0.53 \pm 0.02)$. (Figure 1B, Table 1). Further, Tukey's multiple comparisons test within each group showed no significant difference among the three months in the control group, while in the ADF group, there was a significant difference at $\mathrm{P}=0.003$ in $1^{\text {st }}$ month versus $3^{\text {rd }}$ month. In the TRF group, there was no significant difference among the three months (Table 1).

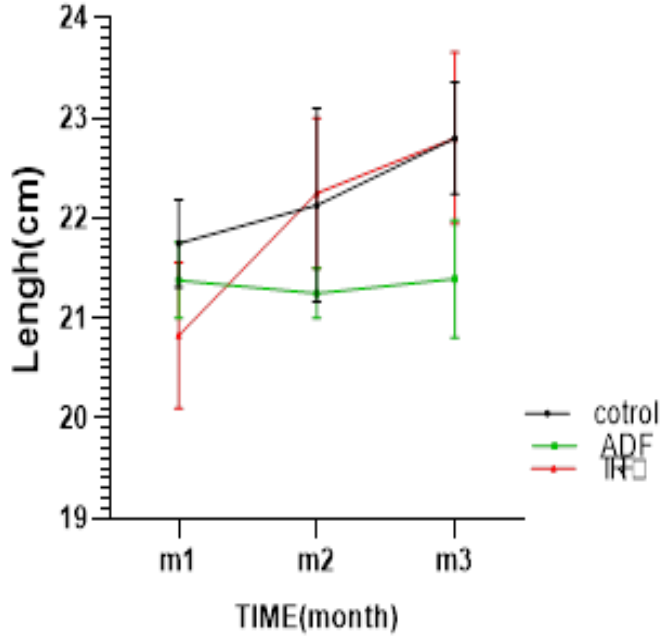

(a)

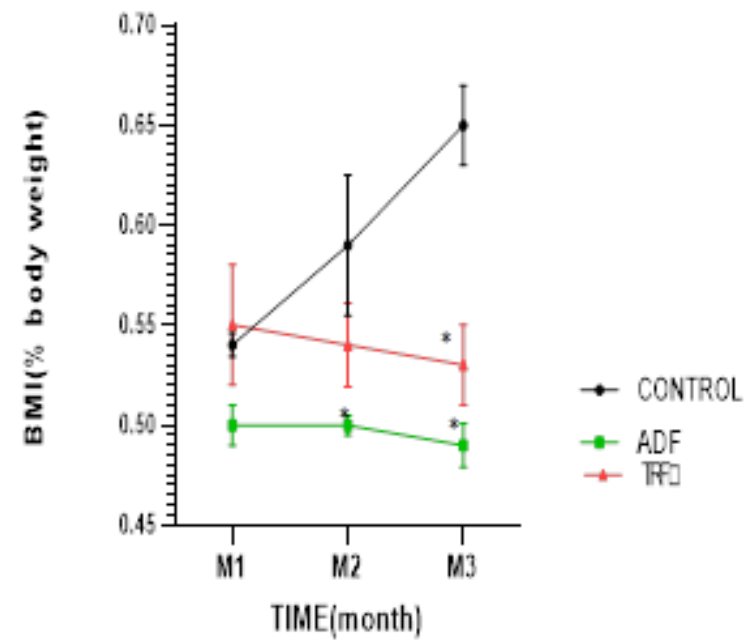

(b)

Figure 1. (A) Effect of Alternate-day fasting and Time-restricted feeding administered for 3 months on body length. The data are presented as mean \pm standard deviation $(n=3)$. No Significant differences were determined using a two-way a nova analysis even among the three months or among the three groups of each month. (B) Effect of Alternate-day fasting and Time-restricted feeding administered for 3 months on body mass index (BMI). The data are presented as mean \pm standard deviation $(n=3)$. Significant differences were determined using a two-way a nova analysis followed by the posthoc Tukey's index (ADF * $\mathrm{p}=0.01$ versus the ad libitum control diet in $2^{\text {nd }}$ month and $* \mathrm{p}<0.0001$ versus control in $3^{\text {rd }}$ month. For TRF $* \mathrm{p}=0.001$ versus the control group in the $3^{\text {rd }}$ month. i.e., within the $1^{\text {st }}$ month, there is no significant difference among the three groups. Within the

$2^{\text {nd }}$ month, a significant difference of control versus $\mathrm{ADF} * \mathrm{p}=0.01$. Within the $3^{\text {rd }}$ month, a significant difference of Control group versus $\mathrm{ADF}^{*} \mathrm{P}<0.0001$ and control group versus $\mathrm{TRF}^{*} \mathrm{P}=0.001$.

By verifying the present results with the previous results, the significant difference in BMI appears in the ADF group in both 2nd and 3rd months compared to the c group, while the TRF group shows a significant difference in $3^{\text {rd }}$ month compared with the $\mathrm{c}$ group. This clears that ADF has a more strict effect in lowering BMI than TRF due to longer time fasting enhances weight loss and agrees with the previous results [14,15].

\subsection{Triacylglycerol TAG $(\mathrm{mg} / \mathrm{dl})$ in different fasting protocols (ADF or TRF) for 3 months.}

The results two ways ANOVA has shown that interaction $p$ value $=0.06$ (nonsignificant), row factor (among three months) $\mathrm{P}=0.002$, column factor (among groups in each month) $\mathrm{P}=0.0001$.

By further Tukey multiple comparisons within each month: $1^{\text {st }}$ month, there was no significant difference. Within the $2^{\text {nd }}$ month, a significant difference has found in the control 
group versus $\mathrm{ADF} * \mathrm{P}=0.0007(\mathrm{C}=101.9 \pm 12.12, \mathrm{ADF}=62.97 \pm 2068)$ and a significant difference in $\mathrm{ADF}$ versus $\mathrm{TRF}^{*} \mathrm{P}=0.008(\mathrm{ADF}=62.97 \pm 2.68, \mathrm{TRF}=92.53 \pm 5.05)$. Within the $3^{\text {rd }}$ month, a significant difference in control versus $\mathrm{ADF}^{*} \mathrm{P}=0.001(\mathrm{C}=92.63 \pm 3.79, \mathrm{ADF}=55.75 \pm 103)$. (Figure 2, Table 2). Tukey's multiple comparisons test within each group showed that there was no significant difference among the three months in the control group while in the ADF group, there was a significant difference at $\mathrm{P}=0.0008$ in $1^{\text {st }}$ month versus $2^{\text {nd }}$ month and in the TRF group, there was no significant difference among the three months (Table 2).

Table 2. Triacylglycerol (TAG) (mg/dl) in different fasting protocols (ADF or TRF) for 3 months.

\begin{tabular}{c|c|c|c|c|c} 
& & control & ADF & TRF & \\
\hline & TAG & & & & \\
\hline $1^{\text {st }}$ month & & $102.93 \pm 3.2^{\mathrm{a}}$ & $94.4 \pm 4.27^{\mathrm{a}}$ & $91.00 \pm 9.98^{\mathrm{ab}}$ & \multirow{2}{*}{$0.049^{*}$} \\
\hline $2 \mathrm{~d}$ month & & $101.9 \pm 12.12^{\mathrm{a}}$ & $62.97 \pm 2.68^{\mathrm{bc}}$ & $92.53 \pm 5.05^{\mathrm{ab}}$ &
\end{tabular}

Group C: control group, group ADF: alternate fasting group, TRF: time-restricted feeding group, group, m1: month 1, vs.: versus. Two ways ANOVA, by Tukey's multiple comparisons test within each month cleared that: TAG in ADF is a significant difference from c group in $2^{\text {nd }}$ and $3^{\text {rd }}$ months; ADF in $2^{\text {nd }}$ month is differently significant with those of TRF group. By further Tukey's multiple comparisons test within each group, it was shown that there was no significant difference among the three months in the control group while in the ADF group, there was a significant difference at $\mathrm{P}=0.0008$ in $1^{\text {st }}$ month versus $2^{\text {nd }}$ month and the TRF group, there was no significant difference among the three months.

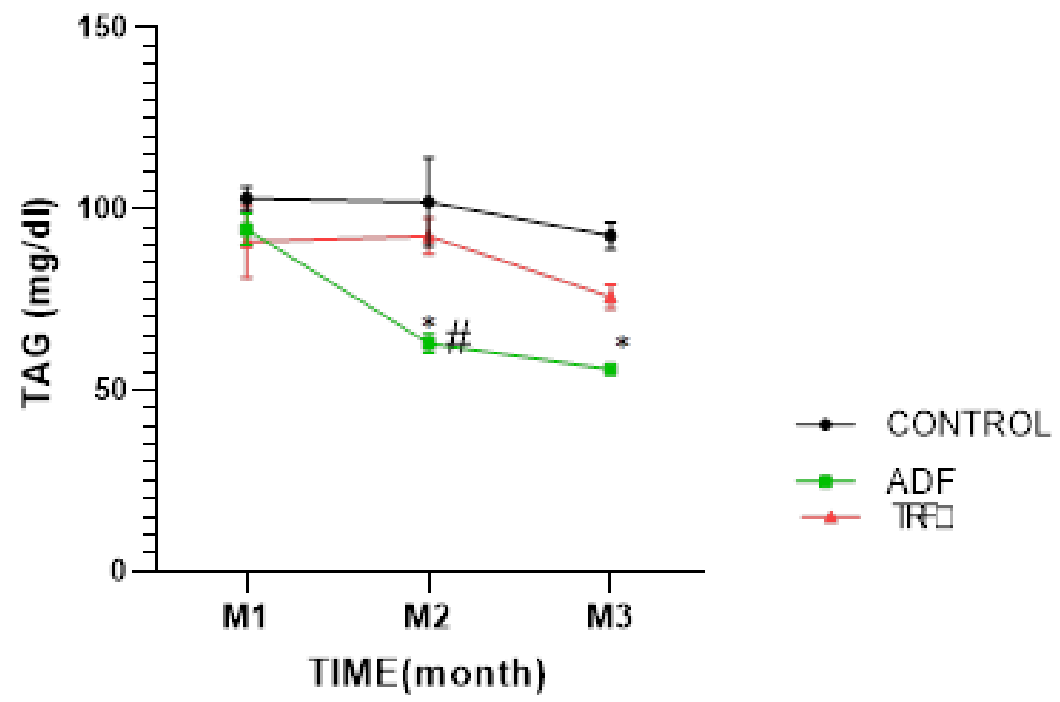

Figure 2. Effect of Alternate-day fasting and Time-restricted feeding administered for 3 months on Tri acyl glycerol (TAG). The data are presented as mean \pm standard deviation $(n=3)$. Significant differences were determined using a two-way a nova analysis followed by the posthoc Tukey's restored $* \mathrm{p}=0.0007$ versus the ad libitum control diet in $2^{\text {nd }}$ month and $* p=0.001$ in $3^{\text {rd }}$ month and $\# p=0.008$ versus Time-restricted feeding in $2^{\text {nd }}$ month. i.e., By further Tukey multiple comparisons within each month: $1^{\text {st }}$ month, there was no significant difference. Within $2^{\text {nd }}$ month significant difference has found in the control group versus $\mathrm{ADF} * \mathrm{P}=0.0007$ and a significant difference in $\mathrm{ADF}$ versus $\mathrm{TRF}^{*} \mathrm{P}=0.008$. Within $3^{\text {rd }}$ month a significant difference in control versus $\mathrm{ADF} * \mathrm{P}=0.001$.

To verify if the obtained results are correct or not, a comparative study has been done with the available literature [16] and [18] in the absence of a few parameters and found good agreement. The present results show that ADF lower TAG conc in $2^{\text {nd }}$ in comparison with the both control group and TRF group while ADF shows significant lowering in TAG conc in $3^{\text {rd }}$ month in comparison with control only. TRF shows a lowering in TAG conc in comparison with the $\mathrm{c}$ group in but it was not significant. 
3.3. MDA (nmol/10dl) levels in ADF or TRF protocols for 3 months.

By two ways ANOVA, it was found that interaction $\mathrm{P}=0.0008$, Row factor (among 3 months) $\mathrm{P}=0.0006$, Column factor (among 3 groups in each month) $\mathrm{P}<0.0001$. By multiple comparisons, findings have reported that within $1^{\text {st }}$ month a significant difference in control versus $\mathrm{AD}$ group at $\mathrm{P}<0.0001(152.00 \pm 5.13,40.0 \pm 3.60)$ and control verses TRF $\mathrm{P}<0,0001(152.00 \pm 5.13,79.67 \pm 4.17)$ and $\mathrm{ADF}$ versus $\mathrm{TRFP}=0.0001(40.0 \pm 3.60,79.67 \pm 4.17)$. Within $2^{\text {nd }}$ month $\mathrm{C}$ group versus $\mathrm{ADF}^{*} \mathrm{P}<0.0001(128.67 \pm 2.03,28.67 \pm 0.88)$ and $\mathrm{C}$ group versus $\mathrm{TRF}^{*} \mathrm{P}<0.0001(128.67 \pm 2.03,75.67 \pm 3.71)$ and $\mathrm{ADF}$ versus $* \mathrm{P}<0.0001(28.67 \pm 0.88$, $75.67 \pm 3.71)$.

Within $3^{\text {rd }}$ month $\mathrm{C}$ group vs. $\mathrm{ADF}^{*} \mathrm{P}<0.0001(144.33 \pm 3.93,28.67 \pm 0.88)$ and $\mathrm{C}$ group vs. $\mathrm{TRF}^{*} \mathrm{P}<0.0001(144.33 \pm 3.93,64.67 \pm 1.76)$ and $\mathrm{ADF}$ vs. $\mathrm{TRF} * \mathrm{P}=009(48.67 \pm 2.60$, 64.67 \pm 1.76 ). (Figure 3, Table 3). Tukey's multiple comparisons test further within each group revealed that in the ADF group, there was a significant difference at $\mathrm{P}=0.001$ in the $2^{\text {nd }}$ month versus $3^{\text {rd }}$ month, while in the TRF, there was a significant difference at $\mathrm{P}=0.001$ in $1^{\text {st }}$ month versus $3^{\text {rd }}$ month (Table 3 ).

Table 3. MDA level(nmol/10dl) levels in ADF or TRF protocols for 3 months.

\begin{tabular}{c|c|c|c|c} 
MDA & Control & ADF & TRF & P-value \\
\cline { 1 - 3 } $\mathbf{1}^{\text {st }}$ month & $152.00 \pm 5.13^{\mathrm{e}}$ & $40.0 \pm 3.60^{\mathrm{a}}$ & $79.67 \pm 4.17^{\mathrm{d}}$ & \multirow{2}{*}{$=0.0006^{* * *}$} \\
\cline { 1 - 3 } $\mathbf{2 d}$ month & $128.67 \pm 2.03^{\mathrm{e}}$ & $28.67 \pm 0.88^{\mathrm{a}}$ & $75.67 \pm 3.71^{\mathrm{c}}$ & \\
\cline { 1 - 3 } $\mathbf{3}^{\text {rd }}$ month & $144.33 \pm 3.93^{\mathrm{e}}$ & $48.67 \pm 2.60^{\mathrm{b}}$ & $64.67 \pm 1.76^{\mathrm{c}}$ &
\end{tabular}

Group C: control group, group ADF: alternate fasting group, TRF: time-restricted feeding group, MDA: malondialdehyde. Group, m1: month 1, vs.: versus. Two ways ANOVA, by Tukey's multiple comparisons test within each month, cleared that MDA in ADF is a significant difference from c group and TRF group in $1^{\text {st }}, 2^{\text {nd }}$ and $3^{\text {rd }}$ months; TRF in $1^{\text {st }}, 2^{\text {nd }}$ and $3^{\text {rd }}$ month is differently significant with those of $\mathrm{c}$ group. By further Tukey's multiple comparisons test within each: In ADFm2 vsm3 significant at $\mathrm{P}=0.001$. In TRFm1 vs m3 significant at $\mathrm{P}=0.01$.

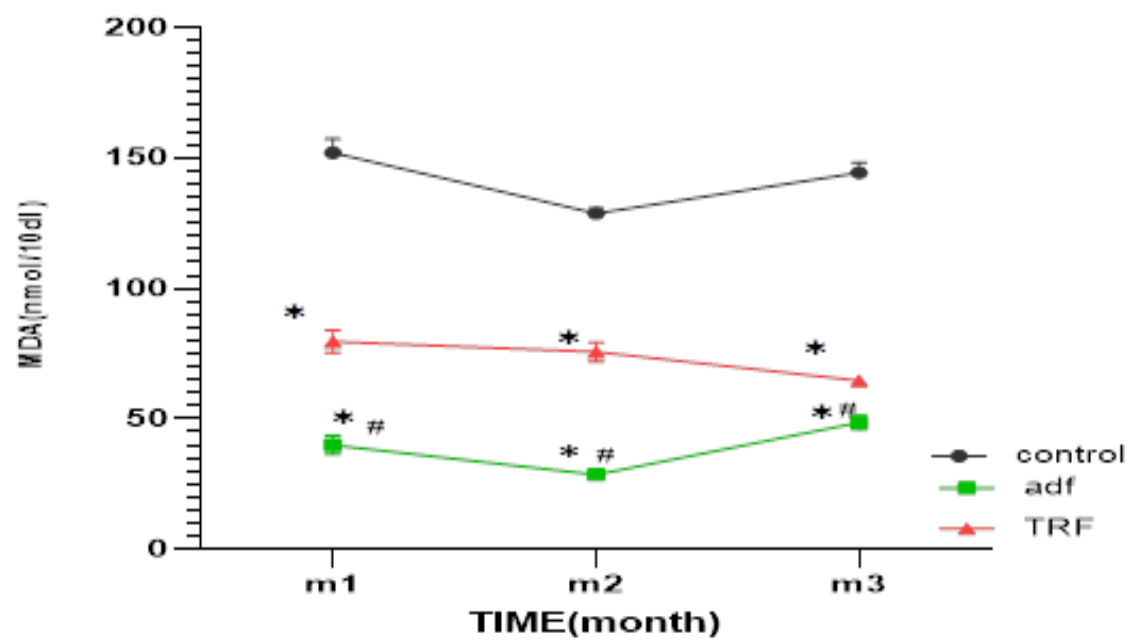

Figure 3. Effect of Alternate-day fasting and Time-restricted feeding administered for 3 months on

Malondialdehyde conc (MDA). The data are presented as mean \pm standard deviation $(n=3)$. Significant differences were determined using a two-way a nova analysis followed by the posthoc Tukey's test. *p $<0.0001$ versus the ad libitum control diet and $\# \mathrm{p}<0.0001$ versus Time-restricted feeding in all the 3 months. Both ADF and TRF decreases oxidative stress parameter (MDA) level starting from $1^{\text {st }}$ month till $3^{\text {rd }}$ month. ADF has a significant decrease in all three months compared to the control group and TRF group, while the TRF group shows a significant decrease in all three months compared to the control group only. Within each group, MDA level ADF 2nd month is lower than $3^{\text {rd }}$ month, while in TRF MDA level in $3^{\text {rd }}$ month was lower than $2^{\text {nd }}$ month. By further multiple comparisons, Tukey's multiple comparisons test within each: In ADFm2 vsm3 significant at $\mathrm{P}=0.001$. In TRFm1 vs $\mathrm{m} 3$ significant at $\mathrm{P}=0.01$. 
A comparative study has been done with the available literature [5] and found good agreement to verify whether the obtained results are correct or not.

The present study results showed that plasma MDA concentrations in Sprague Dawley rats subjected to intermittent fasting were lower than the groups not subjected to intermittent fasting. This study is in agreement with a previous study carried out by Titis Nurmasitoh et $a l ., 2018$ who found that intermittent fasting decreased oxidative stress as shown by the decrease in MDA level, TAG concentration [5].

\subsection{TAC (nmol Trolox equ/10ml) levels ADF or TRF protocols for 3 months.}

The finding has reported that interaction $\mathrm{P}=0.005$, Row factor (among the three months) $\mathrm{P}=0.002$, column factor (within each month) $<0.0001$.

More multiple comparisons have delivered that within $1^{\text {st }}$ month $* \mathrm{P} \leq 0.0001$ control group vs. ADF $(6.67 \pm 0.88,19.0 \pm 0.58)$ and control group vs. TRF $(6.67 \pm 0.88,10.93 \pm 0.29)$ and ADF vs. TRF $(19.0 \pm 0.58,10.93 \pm 0.29)$. Within $2^{\text {nd }}$ monthP $\leq 0.0001$ at control vs $\operatorname{ADF}(4.83 \pm 0.60,19.17 \pm 0.17)$, Control vs TRF $(4.83 \pm 0.60) ,12.50 \pm 0.25^{\mathrm{c}}$ and $\mathrm{ADF}$ vs TRF $(19.17 \pm 0.17,12.50 \pm 0.25)$. Within $3^{\text {rd }}$ monthP $\leq 0.0001$ control vs. $A D F(4.17 \pm 0.17,15.67 \pm 0.88)$, control vs. TRF $(4.17 \pm 0.17,11.33 \pm 0.33)$ and ADF vs. TRF(15.67 $\pm 0.88,11.33 \pm 0.33)$.(Figure 4, Table 4) By further Tukey's multiple comparisons test within each: In ADF month 1 versus month 3 significant at $\mathrm{P}=0.002$, month 2 vs. month 3significant at $\mathrm{P}=0.001$. In TRF no significant difference among the three groups. (Table 4).

Table 4. TAC (nmol Trolox equ/10ml) levels ADF or TRF protocols for 3 months.

\begin{tabular}{l|l|l|l|l}
\multicolumn{1}{c}{ TAC } & \multicolumn{1}{c}{ control } & \multicolumn{1}{c}{ ADF } & TRF & P-value \\
\hline $\mathbf{1}^{\text {st }}$ month & $6.67 \pm 0.88^{\mathrm{d}}$ & $19.0 \pm 0.58^{\mathrm{a}}$ & $10.93 \pm 0.29^{\mathrm{c}}$ & \multirow{2}{*}{$0.001^{* *}$} \\
\hline $\mathbf{2}^{\text {nd }}$ month & $4.83 \pm 0.60^{\mathrm{d}}$ & $19.17 \pm 0.17^{\mathrm{a}}$ & $12.50 \pm 0.25^{\mathrm{c}}$ & \\
\hline $\mathbf{3}^{\text {rd }}$ month & $4.17 \pm 0.17^{\mathrm{d}}$ & $15.67 \pm 0.88^{\mathrm{b}}$ & $11.33 \pm 0.33^{\mathrm{c}}$ &
\end{tabular}

Group C: control group, group ADF: alternate fasting group, TRF: time-restricted feeding group. TAC: Total antioxidant capacity. Group, m1: month 1, vs.: versus. Two ways ANOVA, by Tukey's multiple comparisons test within each month, cleared that TAC in ADF is significantly different from the c group and the TRF group in the $1^{\text {st }}, 2^{\text {nd }}$, and $3^{\text {rd }}$ months; TRF in the $1^{\text {st }}, 2^{\text {nd }}$, and $3^{\text {rd }}$ month is differently significant with those of $c$ group. By further Tukey's multiple comparisons test within each: In ADFm1 vs. m3 significant at P=0.002, m2 vs. m3 significant at $\mathrm{P}=0.001 \mathrm{In} \mathrm{TRF}$, no significant difference among the three groups.

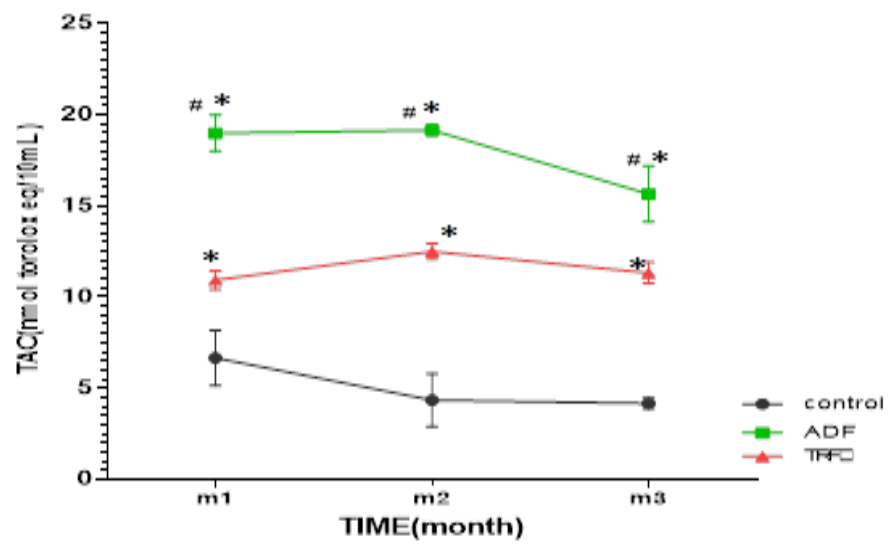

Figure 4. Effect of Alternate-day fasting and Time-restricted feeding administered for 3 months on Total antioxidant capacity (TAC). The data are presented as mean \pm standard deviation $(n=3)$. Significant differences were determined using a two-way a nova analysis followed by the posthoc Tukey's test. *p $\leq$ 0.0001 versus the ad libitum control diet and $\# \mathrm{p} \leq 0.0001$ versus Time-restricted feeding in all the 3 months. Further Tukey's multiple comparisons test within each: In ADF month 1 versus month 3 significant at $\mathrm{P}=0.002$, month 2 vs. month 3signoficant at $\mathrm{P}=0.001$ In TRF no significant difference among the three groups. 
To verify if the obtained results are correct or not, a comparative study has been done with the available literature and found good agreement.

Also, this study is current with a previous trial carried out by Utami Mulyaningrum et al., 2021 who reported that Dawood fasting (DF) could become an alternative to food restriction to improve levels of SOD, GPx, and Cat antioxidant enzymes. This means increasing TAC level by DF[23] [32]. Also, this study is in line with a previous study conducted by Carlos Vinicius Dalto da Rosa et al., 2018. They reported that the antioxidant capacity was improved in the plasma of DER (Diabetic with food restriction) group, as food restriction protocol (FR) consisted of receiving only $50 \%$ of the average food intake of the control group (C), which served as the basis for all groups. Also, in their results, there was a slight increase in TAC of CCR (control with food restriction) group [32], taking into consideration that Intermittent fasting is more strict action rather than food restriction, and the healthy rats could have higher TAC level than those diabetic rats.

This shows that oxidative stress in rats may be minimized through intermittent fasting. Malondialdehyde (MDA) is the main product of lipid peroxidation and is used to determine the number of reactive oxygen species (ROS) produced by oxidative stress [5]. This result is in line with the theory on dietary restriction effectiveness, involving intermittent fasting. Intermittent fasting is frequently accompanied by the inhibition of oxidative stress in the body. It is more pronounced that excessive dietary calories induce lipid peroxidation. Polyunsaturated fatty acids are easily oxidized into free radicals and other reactive compounds like $\mathrm{H}_{2} \mathrm{O}_{2}$. Lipid peroxidation is a cellular injury mechanism and is an indicator of oxidative stress in cells and tissues [5,21]. Lipid endoperoxides coming from polyunsaturated fatty acids are unstable and are changed into complex compounds involving reactive carbonyls, particularly MDA[5,33]. Restriction of calories and control of the number of calories entering the body are expected to suppress and manage oxidative stress in tissues. Thus, the concentrations of MDA formed in the body also become less [5,33]. The present study results also have reported lower TAG in rats subjected to intermittent fasting compared with groups not subjected to intermittent fasting.

Moreover, in agreement with the present study, Françoise Wilhelmi de Toledo et al., 2020 also state that humans have cleared that a 10-day fasting protocol leads to weight loss, improved cardiovascular parameters, and decreased lipid peroxidation, and elevation of antioxidant capacity of plasma in 109 individuals. Their protocol involved discrimination of the individuals into three groups based on their baseline (i.e., pre-fasting) GSH values and found that the impact of this fasting regimen on the lipid peroxidation and total antioxidant capacity was the same in the three groups [10].

The present study proved the benefits of IF (ADF and TRF) and has distinguished that ADF is more effective and strict action than TRF in decreasing MDA level and increasing TAC level, which can be attributed to ADF longer fasting period than TRF. Also, this study has proved that MDA level and TAC level are inversely correlated with the same manner if the trial is under the same conditions as the $2^{\text {nd }}$ month of ADF shows the lowest conc of ADF and the highest level of TAC.

Taken together, this study and previous studies results, there is a need to carry out further studies to distinguish the most effective period of time of ADF or TRF for the best reduction of oxidative stress and increasing TAC level. Moreover, extra explorations might be carried out regarding the parameters that can be affected by IF protocols. The negative side which may occur in this trial could also have more investigation. The present study still has some limitations, like the absence of baseline data. However, there are control groups for 
comparison. The clinical implication of the present study is that IF (ADF and TRF) would be effective in obesity and as a prophylactic way against lifestyle complications like coronary heart diseases, metabolic syndrome, and obesity. ADF is a more effective and strict action for those who can tolerate it.

\section{Conclusions}

The risk of chronic diseases like cardiovascular and cancer can be lowered by lowering oxidative stress through IF, which can elevate life- and health-span by weight and fat loss and through causing a decline in reactive oxygen species (ROS) production and amelioration of lipid metabolism, increased cellular stress resistance and inflammation reduction $[10,11]$.

Intermittent fasting ADF and TRF may decrease oxidative stress as shown by the decrease in MDA, TAG concentrations, and increased TAC level. MDA level is inversely proportioned with TAC level in the same manner if the conditions are constant. IF is considered an alternative lifestyle to suppress imbalanced oxidative stress, which may further limit various degenerative diseases. ADF is a more effective and strict action for those who can tolerate it.

\section{Funding}

This research received no external funding.

\section{Acknowledgments}

This paper has no acknowledgment.

\section{Conflicts of Interest}

The authors declare no conflicts of interest, financial or otherwise.

\section{Ethics statement}

All animal experiments were approved by the Faculty of Veterinary Medicine, Zagazig University Animal Research Ethics, and were done according to their Animal Care guidelines (ZU-IACUC/2/F/195/2019).

\section{References}

1. Margină, D.; Ungurianu, A.; Purdel, C.; Nițulescu, G.M.; Tsoukalas, D.; Sarandi, E.; Thanasoula, M.; Burykina, T.I.; Tekos, F.; Buha, A.; et al. Analysis of the intricate effects of polyunsaturated fatty acids and polyphenols on inflammatory pathways in health and disease. Food Chem Toxicol 2020, 143, 111558111558, https://doi.org/10.1016/j.fct.2020.111558.

2. Margină, D.; Ungurianu, A.; Purdel, C.; Tsoukalas, D.; Sarandi, E.; Thanasoula, M.; Tekos, F.; Mesnage, R.; Kouretas, D.; Tsatsakis, A. Chronic Inflammation in the Context of Everyday Life: Dietary Changes as Mitigating Factors. Int J Environ Res Public Health 2020, 17, 4135, https://doi.org/10.3390/ijerph17114135.

3. Nowosad, K.; Sujka, M. Effect of Various Types of Intermittent Fasting (IF) on Weight Loss and Improvement of Diabetic Parameters in Human. Current nutrition reports 2021, 10, 146-154, https://doi.org/10.1007/s13668-021-00353-5.

4. Ganesan, K.; Habboush, Y.; Dagogo-Jack, S. Calorie Restriction and Intermittent Fasting: Impact on Glycemic Control in People With Diabetes. Diabetes spectrum : a publication of the American Diabetes Association 2020, 33, 143-148, https://doi.org/10.2337/ds19-0064.

5. Nurmasitoh, T.; Utami, S.Y.; Kusumawardani, E.; Najmuddin, A.A.; Fidianingsih, I. Intermittent fasting decreases oxidative stress parameters in Wistar rats (Rattus norvegicus). Universa Medicina 2018, 37, 31-38, https://doi.org/10.18051/UnivMed.2018.v37.31-38. 
6. Sabitha, K.; Venugopal, B.; Rafi, M.; Ramana, K.V. Role of Antioxidant Enzymes in Glucose and Lipid Metabolism in Association with Obesityand Type 2 Diabetes. American Journal of Medical Sciences and Medicine 2014, 2, 21-24, https://doi.org/10.12691/ajmsm-2-1-5.

7. Dong, T.A.; Sandesara, P.B.; Dhindsa, D.S.; Mehta, A.; Arneson, L.C.; Dollar, A.L.; Taub, P.R.; Sperling, L.S. Intermittent Fasting: A Heart Healthy Dietary Pattern? The American journal of medicine 2020, 133, 901-907, https://doi.org/10.1016/j.amjmed.2020.03.030.

8. Chaix, A.; Manoogian, E.N.C.; Melkani, G.C.; Panda, S. Time-Restricted Eating to Prevent and Manage Chronic Metabolic Diseases. Annual review of nutrition 2019, 39, 291-315, https://doi.org/10.1146/annurevnutr-082018-124320.

9. Mattson, M.P.; Longo, V.D.; Harvie, M. Impact of intermittent fasting on health and disease processes. Ageing Res Rev 2017, 39, 46-58, https://doi.org/10.1016/j.arr.2016.10.005.

10. Wilhelmi de Toledo, F.; Grundler, F.; Goutzourelas, N.; Tekos, F.; Vassi, E.; Mesnage, R.; Kouretas, D. Influence of Long-Term Fasting on Blood Redox Status in Humans. Antioxidants (Basel) 2020, 9, 496, https://doi.org/10.3390/antiox9060496.

11. de Cabo, R.; Mattson, M.P. Effects of Intermittent Fasting on Health, Aging, and Disease. The New England journal of medicine 2019, 381, 2541-2551, https://doi.org/10.1056/NEJMra1905136.

12. Anton, S.D.; Moehl, K.; Donahoo, W.T.; Marosi, K.; Lee, S.A.; Mainous, A.G., 3rd; Leeuwenburgh, C.; Mattson, M.P. Flipping the Metabolic Switch: Understanding and Applying the Health Benefits of Fasting. Obesity (Silver Spring) 2018, 26, 254-268, https://doi.org/10.1002/oby.22065.

13. Mattson, M.P.; Moehl, K.; Ghena, N.; Schmaedick, M.; Cheng, A. Intermittent metabolic switching, neuroplasticity and brain health. Nature reviews. Neuroscience 2018, 19, 63-80, https://doi.org/10.1038/nrn.2017.156.

14. Enríquez Guerrero, A.; San Mauro Martín, I.; Garicano Vilar, E.; Camina Martín, M.A. Effectiveness of an intermittent fasting diet versus continuous energy restriction on anthropometric measurements, body composition and lipid profile in overweight and obese adults: a meta-analysis. Eur J Clin Nutr 2021, 75, 1024-1039, https://doi.org/10.1038/s41430-020-00821-1.

15. Cui, Y.; Cai, T.; Zhou, Z.; Mu, Y.; Lu, Y.; Gao, Z.; Wu, J.; Zhang, Y. Health Effects of Alternate-Day Fasting in Adults: A Systematic Review and Meta-Analysis. Front Nutr 2020, 7, 586036-586036, https://doi.org/10.3389/fnut.2020.586036.

16. Meng, H.; Zhu, L.; Kord-Varkaneh, H.; H, O.S.; Tinsley, G.M.; Fu, P. Effects of intermittent fasting and energy-restricted diets on lipid profile: A systematic review and meta-analysis. Nutrition (Burbank, Los Angeles County, Calif.) 2020, 77, 110801, https://doi.org/10.1016/j.nut.2020.110801.

17. Lee, J.H.; Verma, N.; Thakkar, N.; Yeung, C.; Sung, H.K. Intermittent Fasting: Physiological Implications on Outcomes in Mice and Men. Physiology (Bethesda, Md.) 2020, 35, 185-195, https://doi.org/10.1152/physiol.00030.2019.

18. Cienfuegos, S.; Gabel, K.; Kalam, F.; Ezpeleta, M.; Wiseman, E.; Pavlou, V.; Lin, S.; Oliveira, M.L.; Varady, K.A. Effects of 4- and 6-h Time-Restricted Feeding on Weight and Cardiometabolic Health: A Randomized Controlled Trial in Adults with Obesity. Cell metabolism 2020, 32, 366-378.e363, https://doi.org/10.1016/j.cmet.2020.06.018.

19. Stekovic, S.; Hofer, S.J.; Tripolt, N.; Aon, M.A.; Royer, P.; Pein, L.; Stadler, J.T.; Pendl, T.; Prietl, B.; Url, J.; et al. Alternate Day Fasting Improves Physiological and Molecular Markers of Aging in Healthy, Nonobese Humans. Cell metabolism 2019, 30, 462-476.e466, https://doi.org/10.1016/j.cmet.2019.07.016.

20. Ensminger, D.C.; Salvador-Pascual, A.; Arango, B.G.; Allen, K.N.; Vázquez-Medina, J.P. Fasting ameliorates oxidative stress: A review of physiological strategies across life history events in wild vertebrates. Comparative biochemistry and physiology. Part A, Molecular \& integrative physiology 2021, 256, 110929, https://doi.org/10.1016/j.cbpa.2021.110929.

21. Chausse, B.; Vieira-Lara, M.A.; Sanchez, A.B.; Medeiros, M.H.; Kowaltowski, A.J. Intermittent fasting results in tissue-specific changes in bioenergetics and redox state. PloS one 2015, 10, e0120413, https://doi.org/10.1371/journal.pone.0120413.

22. Trepanowski, J.F.; Canale, R.E.; Marshall, K.E.; Kabir, M.M.; Bloomer, R.J. Impact of caloric and dietary restriction regimens on markers of health and longevity in humans and animals: a summary of available findings. Nutrition journal 2011, 10, 107, https://doi.org/10.1186/1475-2891-10-107.

23. Mulyaningrum, U.; Muttaqina, A.F.; Idninda, A.N.; Pulungan, N.; Agustiningtyas, I.; Fidianingsih, I. Effect of Dawood Fasting on the Increased Level of Antioxidant Enzymes. Open Access Macedonian Journal of Medical Sciences 2021, 9, 1-6, https://doi.org/10.3889/oamjms.2021.4175.

24. Sorensen, M.; Sanz, A.; Gómez, J.; Pamplona, R.; Portero-Otín, M.; Gredilla, R.; Barja, G. Effects of fasting on oxidative stress in rat liver mitochondria. Free radical research 2006, 40, 339-347, https://doi.org/10.1080/10715760500250182.

25. Pizzino, G.; Irrera, N.; Cucinotta, M.; Pallio, G.; Mannino, F.; Arcoraci, V.; Squadrito, F.; Altavilla, D.; Bitto, A. Oxidative Stress: Harms and Benefits for Human Health. Oxid Med Cell Longev 2017, 2017, 84167638416763, https://doi.org/10.1155/2017/8416763.

26. Fukai, T.; Ushio-Fukai, M. Superoxide dismutases: role in redox signaling, vascular function, and diseases. Antioxidants \& redox signaling 2011, 15, 1583-1606, https://doi.org/10.1089/ars.2011.3999. 
27. Mulyaningrum, U.; Muttaqina, A.; Idninda, A.; Pulungan, N.; Agustiningtyas, I.; Fidianingsih, I. Effect of Dawood Fasting on the Increased Level of Antioxidant Enzymes. Open Access Macedonian Journal of Medical Sciences 2021, 9, 1-6, https://doi.org/10.3889/oamjms.2021.4175.

28. Azevedo, F.R.; Ikeoka, D.; Caramelli, B. Effects of intermittent fasting on metabolism in men. Revista da Associacao Medica Brasileira 2013, 59, 167-173, https://doi.org/10.1016/j.ramb.2012.09.003.

29. Bracht, A.; Silveira, S.S.; Castro-Ghizoni, C.V.; Sá-Nakanishi, A.B.; Oliveira, M.R.; Bersani-Amado, C.A.; Peralta, R.M.; Comar, J.F. Oxidative changes in the blood and serum albumin differentiate rats with monoarthritis and polyarthritis. SpringerPlus 2016, 5, 36, https://doi.org/10.1186/s40064-016-1671-1.

30. Grundler, F.; Mesnage, R.; Goutzourelas, N.; Tekos, F.; Makri, S.; Brack, M.; Kouretas, D.; Wilhelmi de Toledo, F. Interplay between oxidative damage, the redox status, and metabolic biomarkers during long-term fasting. Food Chem Toxicol 2020, 145, 111701-111701, https://doi.org/10.1016/j.fct.2020.111701.

31. Levine, R.L.; Garland, D.; Oliver, C.N.; Amici, A.; Climent, I.; Lenz, A.G.; Ahn, B.W.; Shaltiel, S.; Stadtman, E.R. Determination of carbonyl content in oxidatively modified proteins. Methods in enzymology 1990, 186, 464-478, https://doi.org/10.1016/0076-6879(90)86141-h.

32. Rosa, C.; Campos, J.M.; AB, S.N.; Comar, J.F.; Martins, I.P.; Mathias, P.C.F.; Pedrosa, M.M.D.; Godoi, V.A.F.; Natali, M.R.M. Food restriction promotes damage reduction in rat models of type 2 diabetes mellitus. PloS one 2018, 13, e0199479, https://doi.org/10.1371/journal.pone.0199479.

33. Klenk, J.; Rapp, K.; Ulmer, H.; Concin, H.; Nagel, G. Changes of body mass index in relation to mortality: results of a cohort of 42,099 adults. PloS one 2014, 9, e84817, https://doi.org/10.1371/journal.pone.0084817. 